\title{
English Language Teaching to Young Learners: Possible Pitfalls after Lowering the Age of Compulsory English in Pakistan
}

\author{
Muhammad Saboor Hussain \\ Qassim University, Kingdom of Saudi Arabia \\ Islamabad Model College for Boys, H-9 Islamabad, Pakistan \\ E-mail: rajasaboor@hotmail.com \\ Aisha Farid \\ Qassim University, Kingdom of Saudi Arabia \\ Department of Graduate Studies, National University of Modern Languages (NUML), Islamabad, Pakistan
}

Received: 07-02-2013

doi:10.7575/aiac.ijalel.v.2n.3p.95
Accepted: 19-03-2013

Published: 01-05-2013

URL: http://dx.doi.org/10.7575/aiac.ijalel.v.2n.3p.95

\begin{abstract}
The young learners have an inbuilt and inborn capacity of absorbing the language inputs. With the growing age, their absorbing capacity reduces though it gets compensated by experience. The adult age can bring wisdom and knowledge but for acquisition, improvement and development of the skills, particularly the language skills, prime time is the young age. There has been a growing awareness about this in Pakistan where, in recent years, a major shift has taken place i.e., starting compulsory English from class-1 in all private and Government schools instead of class $6^{\text {th }}$ which had been the earlier practice since the independence of the country in 1947. There are many associated complex issues surrounding this new scenario which have emerged due to this major shift and need to be explored, meditated and researched from all the possible dimensions in order to enhance the advantages of the changed paradigm, reduce the risks to the bare minimum and train and fine tune the teachers and the schools to cope with this change in a professional and effective manner.
\end{abstract}

Index Terms: ELT to young learners, lowering the age of compulsory English, possible pitfalls, language acquisition, language learning

\section{Introduction}

\subsection{Problem Statement}

With the increase in population and the growing awareness of the need for learning English, the demand for teachers who can teach English to young learners is increasing all over the world in general and in Pakistan in particular. This realization of focusing on the young learners is also growing due to the fact that focusing on the adult language learners has not paid off as much as was expected as it is evident in the poor results of intermediate and degree students in Pakistan every year. Only in 2007, more than 90 per cent of the students appearing in MA English examination failed. The total number of students appearing in MA English Part-I Examination 2007 was 9068 but only 1477 of them could successfully pass while the overall pass percentage was merely 16.3 per cent. Moreover, the same year, over than 100,000 students of BA/BSc could not get through in the annual examination of the compulsory subject of English conducted by the Punjab University (Khattak, 2007). In addition, even this year, the results of MA English Part-I announced by the Punjab University have shown a very sad picture. Majority failing unveils and exposes the declining and deteriorating standard of education at colleges in general and the poor teaching of the subject of English right from primary level in particular.

The stakeholders have varied opinions about the reasons of the ever increasing failure percentage in MA and BA in the subject of English. Most of the students consider the aggregate system of marking as the most responsible factor for their failure. They also blame the examiners for their sheer irresponsibility in marking and evaluating the papers. Students at MA level also criticize the Punjab University examination system which is the annual system. The claim is that the candidates appearing under semester system examination have more advantage over students appearing under annual examination since the latter has to appear in comprehensive examination. In addition, majority of students who come from the government sector schools put the blame on the authorities for not teaching English at primary level. Moreover, they express their dejection on the ill English language teaching methodologies even at the secondary and higher level. Since the teachers' focus is on having more pass percentages in their classes, their all efforts go in making the students cram the English content, and there is no attention paid towards the students' real English language skills development. As a result, the students reach the higher level without getting the required English language proficiency, and ultimately fail badly in BA/BSc examinations in English subject. During a discussion with the students on the stated 
issue, the students also pointed out another sad aspect of the situation. They commented that the teachers teaching them English in the schools and even in some colleges could not even speak English themselves, so how they could develop the English language skills in their students.

The academicians and educationists are of the view that the main responsibility in this regard lies with the poor schooling particularly in the subject of English. The poor English language teaching eventually leads to the ultimate deterioration in the standard of higher education especially in English language and literature. Thus, they claim that overall standard of English deteriorates right from the beginning. The main causes for deteriorating standards of English as a subject are the burdensome teaching methodology, poor classroom instructions and incompetent English teachers. Next, the situation gets intense because of the dichotomy between the government schools and private English medium schools. The government schools impart education through Urdu as the medium of instruction though English as a subject is also taught. In contrast, almost all the private schools use English as the medium of instruction and there all subjects are taught in English.

It is a fact that the government school teachers, who teach the subject of English, are not fully competent since most of them cannot even communicate in English. When one talks to the college teachers on the issue, they express their disgust on the standard of the students coming to them after successfully getting through the secondary school examination. The students are habitual of cramming and are unable to develop the critical and analytical abilities required for passing the examinations especially in the English subject. The development of students' poor learning abilities at school level is greatly responsible for the higher percentage of failures at BA/BSc and MA in English. In one of the interviews, the chairperson PU Department of English Language \& Literature took the side of the other academicians on the claim that overall standard of the subject of English is deteriorating right from the primary level and expressed her views in these words, "This starts from school level and culminates in MA". She was of the opinion that the students who could make up till MA level were not well prepared; therefore, they could not perform well in the exams and failed. She added, "Our students are not dim but they are not prepared well". She also admitted that there were many loopholes and flaws in the examination system. She explained that there was no perfect system. She was of the view that the teaching community especially at primary level should be improved as the first step towards rectification.

The educationists and the educational policy makers considered all these problems and issues, as a result of which the government of Pakistan decided to focus on the young learners to improve overall English teaching/learning scenario, and in 2009 it was decided that the English language must be taught from class-1 onward. The scenario changed all of a sudden and in all government schools, the teachers started teaching English to the children from class-1 onward. The teachers teaching English to these children or the young learners were no new teachers. The teachers already engaged in teaching other subjects earlier were now made to teach English to these young learners. Later new teachers were hired for the purpose and they have been teaching the young learners without any pre- service teacher training. Teaching young learners requires a lot of attention to acquiring specialized skills for involving the learners in learning. Thus a thorough knowledge of young learners' psychological and emotional development is direly desirable for effective teaching/learning at this level. In this new scenario, there is need to find out the ways of making English language learning/teaching at a lower age more beneficial by addressing the possible pitfall on the way.

The young learners are defined in various ways. In Pakistani context, the term young learners can be used mainly for the group from preschool learners to secondary school learners i.e., roughly the age group 3-16. Hence the teachers who should be trained to tackle the intricacies of learning/teaching process are not only the school teachers but also the college lecturers and professors teaching $1^{\text {st }}$ year classes.

The teachers teaching English to age group 3-16 must be different in many ways from the teachers teaching English to adults. As the young learners need more of sense of security and seek more pleasure, the teachers are required to be more sensitive to their moods. What we have felt after having the experience of teaching both young ones and adults, is that the young learners are more enthusiastic and lively and are in the process of developing their own learning strategies. Therefore, they mainly need good English language models. Moreover, all of them may not respond to an activity in the same way. Therefore, each of them needs individual attention from the teachers. They are more open and cooperative to their peers. They are required to be engaged in a variety of more meaningful group activities rather than being lectured in a traditional way.

\subsection{Basic Research Question}

How can English language learning/teaching situation be improved after lowering the age of compulsory English in Pakistan?

Subsidiary Research Questions

- Why has the age of compulsory English been lowered in Pakistan?

- What are the advantages of starting English language instruction early?

- What are the disadvantages of starting English language instruction early?

- How can the schools and teachers be prepared to handle teaching English to young learners? 


\section{Literature Review}

In order to study the perspective of English language teaching to young learner, there is a need to study the child development which helps understand the requirements for teaching them effectively at such an early stage.

Children are not adults. Until the age of 15 or so they are not capable of reasoning as adults can do. Piaget (the school of cognitive theory) finds intelligence the basic mechanism ensuring equilibrium in the relations between the person and the environment (Piaget, 1950). He is of the view that children primarily learn through imitation and play throughout the first two stages i.e., from infancy to age 7, as they build up symbolic images through internalized activity (Herbert Ginsberg \& Sylvia Opper, 1969). Therefore, the teachers in the primary schools are required to be sensitive to the learners' need and be able to make teaching a fun activity.

B.F. Skinner, the founder of Behaviorism claims that all behavior is learned and that humans enter the world with no innate abilities. He famously said, "Give me a child, and I'll shape him into anything" (Fodder, 1975). Most of the school teachers' self and social image is so low in Pakistan that they do not realize the strength of the shaping hands they have for the new buds given under their charge.

Bruner (1990) discusses the importance of language as a tool for cognitive growth. He has investigated how adults by using language can be the mediators between the child and the world. What is required is that school teachers, through in-service and pre-service training need to be made aware of their different roles whereby they can build connections between the brains of the learners and the real world.

According to Chomsky (Lutteral, 2009), till the critical age, it is acquisition and once the critical age passes, it is learning. In this way, the teachers dealing with the young learners are facilitating the acquisition process and not the learning process. The human brain keeps these grammar switches flipped for a few years only. This span of time when the switches are on is known as the "critical period," and if a child is not exposed to language during this time, he or she will never be able to develop language normally. Hence, English language teachers need to take it equal to a sin using GTM (Grammar Translation Method) in the class during the period of learning. There are certain drawbacks of introducing English to young learners which the teachers need to be aware of in order to address them and solve them in a befitting manner.

The theories and research studies on second language acquisition point out both the advantages and drawbacks of introducing English language to the young learners. Cameron (2001) finds that young learners are keen, enthusiastic, uninhibited, so are or can be easily motivated. But adult learners are at an advantage compared with younger learners in formal learning of grammar in instructional settings (Long, 1979). Ellis found in a research that adult learners have an initial advantage as far as the rate of learning is concerned, particularly grammar and morphology (Ellis, 1994) Lightbown and Spada (1999) advise the teachers and the policy makers to attend to the needs, motivation and contexts of different groups of learners. They suggest that if the required goal is the native like fluency then learning benefits more from an early start, but when the goal is just the communicative ability, the benefits from an early start are not very clear. Thus the teachers dealing with adults do not need to fall into the ditch of disappointment that once the critical age of the learners has gone, not much can be done. We found many college teachers with this plea for their inaction, lack of interest and innovation in their teaching strategies that these students have lost the precious time of learning the language at schools and that school teachers have spoiled them; so, they cannot be taught the language properly. These teachers need to be aware of this present pleasant and positive picture of teaching/learning paradigm.

\section{Methodology and Research}

The research at hand is basically qualitative in nature to get a deeper understanding of the issue under study. A qualitative research mainly focuses on the observation of the participants' behavior in their particular setting to understand realities experienced by the participants as the "insiders". It is also an action research since the researchers included their own experiences as learners and then as teachers at various levels in this study so as to have an insider's view from a very close end.

We visited 25 private and 25 public schools in our hometown viz., Islamabad and following is the qualitative analysis of the data based on our own experience, observation and comparative study of the two perspectives:

In Pakistan, though the private English medium schools had already been giving compulsory English education from the pre-school to the children coming to them, now the government has made it compulsory for all private and public schools (Pakistan development Forum, April 2005). Private English medium schools would arrange for highly qualified and well trained teachers to their students coming to them with high fee. But in public schools where the change has been made all of a sudden, there have risen a number of problems which needed careful planning, adequate support and resources, and close monitoring and evaluation and arrangements. Without proper planning and adequate support, the initiative, however well intentioned, is likely to be counterproductive (Nunan, 1999). While observing different classes in the schools in Rawalpindi and Islamabad, most often we found the baffled teachers dealing with the crowded classes in a rather haphazard and ill planned manner. The sudden introduction of English subject at class-1 has been made without proper planning and preparation. The teachers are confused and baffled. Not having proper training and skills required for the said purpose, they felt so unsecured that they were reluctant in allowing the researchers to visit and observe their classes. They are struggling hard to cope with the new situation.

In fact, the teachers are not well trained and qualified to handle the young learners in English language classes especially. In most of the government primary schools, the teachers cannot communicate in English, and cannot even 
pronounce the English words written in the books properly. Some such examples are "water /wa:tӘr/", "main gate /mæn geit/" and "school/Osku:1/ As a result, the young learners get the wrong models to follow for their initial English language development, and adopt the unfavorable habit of cramming everything coming from their teachers.

Keeping in view the possible problems resulting from the sudden shift to compulsory English education from class-1 in public schools in Pakistan, there is a dire need to attempt to reach the conclusion as to how beneficial this shift may be and how it can be made so if it is not.

Generally speaking, in most of the private schools, it has proved to be beneficial as the feed these schools send to the colleges and universities have been impressive while almost reverse is true in case of pubic/government schools. To add fuel to the fire, the college teaching staff mostly mishandles the $1^{\text {st }}$ year young learners given under their charge, treating them as adult learners right from the day one, unmindful of the transitional processes taking place in them. These baffled young learners, while in a process of transition to adulthood, face the baffled teachers due to the teachers' lack of awareness of educational psychology, non-availability of in-service and pre-service training, illogical seating arrangements, wrong assessment system and faulty teaching aids and material. One of the college students while sharing his view on the issue commented in these words, "we don't even understand what our teacher says in English. He comes to start explaining things in English without caring whether we understand or not....our teacher thinks we have (had) a lot of knowledge in English." Another student complained, "it is not our fault that we are poor and we have come from government schools. If we could not get good English teachers in our schools, at least here in the college, we expect that our teachers should work on our English (language development)." The teachers are of the view that the students reaching college or higher secondary level have crossed the critical time for the language learning development and now it is not possible to engage them in this activity. When we discussed the same issue with the school teachers, they had plethora of complaints. One major view held by most of them was that the students coming to them were to learn two new languages, namely Urdu and English and it became greatly burdensome for both the teachers and the taught.

Nunan's (1999) is an interesting question to start with, "younger the better?" we favor the proposition in the light of our personal and professional experience. As a young learner we were able to absorb five languages but ever since we have grown into a hard and rigid adult, we have been trying to learn the 6th one (Phushto) but many years have passed and we could not master it. We learnt at a very early age our native language i.e. the mother tongue "Potohari" (integral part of our brain), then at an early age, native-like language or the peer language "Punjabi" (almost as strong as our native language). Next, the language we learnt a bit later than that is our national language taught formally in schools "Urdu"; we are ambi-lingual in it (with native speaker like competence), and in the language (English) we learnt a bit later than that, we are compound bilinguals (we think and produce simultaneously). Finally, the one we learnt the last (Arabic), we are coordinate bilinguals, rather less than that (we think in our mother language and try to produce Arabic with a lot of fluctuations).

Our child is 7 years now and studies in class-3. We notice and observe the same pattern in him, the way we had when we were young with a bit of shuffle in the sequence of the languages being learnt. Hence we deduce that at a very early age, no matter how many languages you want to teach the learner, s/he will acquire them all with wonderful pace, astonishing competence and high degree of quality but it has to be done with proper environment, teaching tools, teaching techniques, methods and approaches.

Another positive and plus point which the young learners have is that, most often, they do not develop any affective filter/barrier between their brains and the language inputs provided to them. They do not get blocked by negative emotions like anxiety, inhibition and lack of confidence, the way adult learners often do. The only challenge faced by the language input provider/teacher is to arrest their attention span which a professional and properly trained teacher, even the aware and educated parents, can do very well. Modern day media, cartoon networks and kids' movies can play a pivotal part in enhancing their competence in the target language as well in which the adults seem least interested.

Young learners are better than the adult learners or it is better to start teaching the target language to the young ones rather than the adults. It is high time that the policy makers, educational administrators, and professionals in the field realized this thing so that foundations could be laid down properly and teachers teaching adults could work on constructing buildings on those foundations. The teachers teaching the adults should start working in the areas like concepts formulation, theories making and research culture promotions rather than continuing what should have been completed long ago i.e. language skills development.

\section{Conclusion and Discussion}

Following should be the key considerations for English language teachers in Pakistan:

Does the term "Young Learners" mean small kids going through the experience of acquiring $\mathrm{L}_{1}$ or this term should also be referred to the beginners from any age group on their way to new experience of learning a new language? To our mind there is or should be no distinction except for some minor and procedural one.

Should there be any difference in approach in presenting the language inputs to the kids learning their first language or adults learning a language for the first time? Again the common notion is that there is a marked difference whereas, making this distinction has done more harm than good as there are linguists like Stephen Krashen who no more believe in the distinction between language learning and language acquisition. 
Since the birth of our son, who is now seven years old, we have been observing his English language acquisition and comparing the process with the our adult students who are beginners in English language learning, and we have found many parallels such as initial silent period, pattern of initial utterances, nature of errors and mistakes and sometimes relying on translation from $\mathrm{L}_{1}$ into the target language. Moreover, in the initial part of my (Saboor's) teaching career, I was engaged with the age group of 8-14 years at Army Burn Hall College, Abbotabad, Erkin Grammar School, Rawalpindi and Army Public School and College, Shinkiari, then in a University with the students with the age group of 25-40 and now with 14-20. Still there is a need to explore further whether there exists any remarkable difference as far as language input reception and assimilation is concerned in these different age groups. It is an area to be researched and this paper is a starting point for us in this direction.

In order to help resolve the confusion in the concepts regarding language acquisition and language learning, GTM (Grammar Translation Method), DM (Direct Method) and class environment, two living linguists, Noam Chomsky and Stephen Krashen present some impressive notions. Chomsky believes that language is acquired till the critical age of the learner and after that it is learnt. Thus the teachers at the early stage becomes/should become the facilitators for language acquisition and not language learning. Krashen has presented Natural Approach which does have a great impact on the learning process. We often put it in our teaching practice and results are amazing. The first thing it teaches you is that you learn to treat a child as an adult and an adult as a child (This sentence needs a lot of meditation and reflection). The rest starts flowing automatically in the right direction. Krashen does not believe in the distinction between language acquisition and language learning.

It is commonly held that adults learn the language and young ones acquire it but as far as our personal experience and observation go, we do not find any remarkable difference between language acquisition and learning. Acquisition is when language comes to you and learning is when you go to the language. In either case, it makes no difference to a professional language teacher whether $\mathrm{s} / \mathrm{he}$ takes the learners to the language or brings language to the learners. Our teaching creed is when you stop making this distinction, you tend to be more natural, down to earth and sympathetic to the learners' lapses, errors, mistakes and even blunders and thus become more effective language teacher.

The issue of Urdu use/ mixing while teaching English has taken the shape of serious controversy now in Pakistan. The new entrants in the field with linguistic background or the ones engaged in in-service qualification enhancement and academic and research activities, have a clear cut stance that there should be DM, Eclectic, Communicative, Interactive, Student-centered and project based approaches while imparting language skills of listening, speaking, reading and writing to the learners. The teachers with the rigid and stubborn stance on GTM need to be counseled, molded, reshaped and directed to the culture of change and advancement by promoting a culture of research in general with focused and dedicated funding by government and non-government agencies.

In the first place, having taken the step of lowering down the compulsory English education in Pakistan (Pakistan development Forum, April 2005), the teachers are required to have the basic knowledge of the issues related to ELT. Zubaida Mustafa (2009) opines in a column in the Dawn, "our English-language teaching is not at all up to the mark and the National Education Policy admits that. Hence the problem has to be addressed mainly by training good Englishlanguage teachers. Given the appalling standard of English-language teaching in all schools, with the exception of a few private elite schools, it will prove to be a formidable exercise to upgrade the knowledge of English of thousands of language teachers as well as thousands of those teaching science and mathematics to ensure their proficiency in English". School administrations should conduct workshops and hold in-service and pre-service training and refresher courses and invite distinguished research scholars and academicians and linguists for the concept formation and clarification of the teaching staff on regular and frequent basis.

\section{References}

Cameron, L. (2001). Teaching Languages to Young Learners. Cambridge: Cambridge University Press.

Ellis, R. (1994). The Study of Second Language Acquisition. Oxford: Oxford University Press.

Fodor, J. A., \& T. G. Bever, \&. M. (1975). The Psychology of Language: An Introduction to Psycholinguistics and Generative Grammar. New York: McGraw-Hill.

Government's education Reforms \& Strategy: Pakistan Development Forum. (2005, April 25). Retrieved January 17-12010, 2010, from Education Minister's Presentation at NDC: www.moe.gov.pk/NDC-\%205-Feb-05byEMfinal.ppt

Herbert Ginsburg, A. S. (1969). Piaget's theory of intellectual development. Englewood Cliffs, N.J.: 013493017X $013493007 X$ (pbk.) Prentice-Hall.

Lutteral, A. (2009, Ocober 14). How We Learn Languages: Noam Chomsky's Approach to Language Acquisition. Retrieved January 17, 2010, fromSuite101.com: http://languagestudy.suite101.com/article.cfm/how_we_learn_language Mustafa, Z. (2009, September 2). The Language Enigma. Retrieved January 17, 2010, from dawn.com: http://www.dawn.com/wps/wcm/connect/dawn-content-library/dawn/news/pakistan/16-the-language-enigma-hs-02

Nunan, D. C. (1999). Does younger = better? TESOL Matters, 9(3) , 3.

Piaget, J. (1950). The psychology of intelligence. London: Routledge \& Kegan Paul.

Spada, L. a. (1993). How Languages are Learned. Oxford: Oxford University Press. 